VICTORIA CAMPS

\title{
De la representación a la comunicación
}

S OLO Kant se da cuenta del giro antropológico que, con $\mathcal{S D e s c a r t e s}$ (o, incluso antes, con Bacon), se produce en el pensamiento metafísico. Hablar del yo que conoce y piensa, antes que de las cosas pensadas, para hallar los principios constituyentes, los a priori del conocer. Ahora bien, hablar del yo no es hablar sobre nosotros mismos: de nobis ipsis silemus. No interesa el yo empírico, diferente y mudable: interesa el yo trascendental, que es condición de posibilidad del conocimiento empírico, sin que él, a su vez, sea objeto de tal conocimiento. Un yo fantasma, mero postulado, tan sólo necesario como sujeto de categorías y principios a priori. Modelo conceptual anterior a la experiencia, que constituirá la gramática de la representación del objeto.

Se inicia a partir de ahí un discurso solipsista que da lugar a una serie de tratados sobre el método. Método que quiere garantizar la veracidad del conocimiento del mundo exterior, pero que, a decir verdad, no consigue probar ni la existencia del mundo exterior ni la existencia de los otros sujetos. ¿ Cómo se llega a la cosa en sí, no determinada por el modo de conocer del sujeto? ¿Cómo se llega al alter ego? El yo mismo, la autoconciencia, es incognoscible. Nos conocemos a nosotros mismos en tanto que somos afectados, como fenómenos. El ser pensante, sustancia simple, no es capaz de conocer su sustancia.

"Risa nos da ver al hombre y al mundo separados por la estupenda pretensión de la conjunción", escribe Nietzsche para quien la confrontación entre sujeto (conciencia) y objeto 
responde a la voluntad de juzgar y sojuzgar, medir y negar el mundo por parte de los humanos. De la misma forma que Rousseau siente que el lenguaje es signo de la menesterosidad humana y de sus limitaciones, Nietzsche entiende que la conciencia nace de la necesidad de conocer y expresar las propias limitaciones y miserias, la necesidad de solicitar ayuda. De este modo, la conciencia responde a la urgencia humana de comunicación. Pero esa misma conciencia transforma lo que en el individuo era singular y personal en algo gregario y comunal. Tomar conciencia de algo es generalizarlo, vulgarizarlo. ( $L a$ Gaya Ciencia, 346 y 354). La conciencia recibe tan sólo cuanto se deja traducir a esquemas de carácter social y gregario, es "la voz del rebaño en nosotros". Puesto que la sociedad es la respuesta a una situación de menesterosidad y de conflicto, a la que trata de superar con estructuras y relaciones de dominio, la conciencia - el lenguaje - es la reproducción interna de tal dominio. Los conceptos igualan lo desigual. Con la palabra -el contrato-, el hombre instaura la "ley de la verdad", que es la ley del disimulo. Así, la transformación del sujeto significa, para Nietzsche, ir más allá de la conciencia, es decir, del conflicto; significa instaurar una justicia que no coincida ni con la caridad cristiana ni con la equidad de la moral laica, y transformar la noción de tiempo: pensar en el instante, en la eternidad, para poder amar la vida.

Nos interesa de momento lo que Nietzsche le reprocha a la conciencia y no la imagen que trata de transmitir del hombre nuevo. Lejos de ser ese reducto de pureza, claridad y legitimidad pensado por los filósofos, la conciencia es "la voz del rebaño", nada más y nada menos que mero lenguaje, con todos los lastres que el lenguaje lleva en sí, en tanto expresión de las necesidades humanas y de una forma insuficiente de compensarlas. La palabra, el pacto, bajo una supuesta ley de la verdad, introduce el disimulo, la apariencia y la mentira; bajo un supuesto orden, esconde conflicto, dominio, sojuzgamiento. $\mathrm{Si}$ la conciencia no es más que lenguaje, voz de lo comunal y lo colectivo, el yo aparece como una "rutina gramatical", puesto que no es "más que una hipótesis, una aseveración; sobre todo, no es una "certeza inmediata". Somos nosotros quienes hemos creado la identidad del sujeto, esa alma sustancial e in- 
destructible que, de hecho, no es más que una pluralidad, la estructura social de los instintos y afectos (G.C., 354). La personalidad, viene a decir Nietzsche, es un conjunto de estratos diversos que se equilibran provisionalmente.

Wittgenstein ya ve con claridad que el yo pensante es una ilusión y no existe. "Si yo escribiese un libro El mundo como yo lo encuentro, yo debería referirme en él a mi cuerpo y decir qué miembros obedecen a mi voluntad y cuáles no, etc. Este sería un método para aislar al sujeto o aun mejor para mostrar que en un sentido importante no hay sujeto; precisamente sólo de él no se podría hablar en este libro"'(Tractatus, 5, 631). Sin embargo, también para Wittgenstein hay algo que debe preceder a la experiencia: la lógica, y gracias a ella es posible decir que "el mundo es mi mundo", lo cual "se muestra en que los límites del lenguaje (el único lenguaje que yo entiendo) significan los límites de mi mundo" (Tractatus, 5, 62).

¿El mundo es mi mundo? Sólo en cuanto el mundo es lenguaje y el lenguaje es mi único modo de relacionarme con el mundo. El solipsismo y el realismo han llegado a coincidir por el procedimiento de reducir lo real a la ordenación lógicolingüistica del yo que se lo representa.

Con Wittgenstein se produce el tránsito del giro antropológico al giro lingüístico. El Tractatus oscila aún entre ambas posiciones de forma que el giro lingüístico se da sólo a medias: el tema es el lenguaje, sí, pero en tanto representación de la realidad. El sujeto no es sujeto cognoscente: es sujeto lingüístico, pero sujeto que ha de garantizar su modo de hablar de o de representarse las cosas. El Tractatus sigue siendo un tratado del método de representación. Para superar tal punto de vista será. preciso abdicar de la dualidad lenguaje/mundo, o sujeto/objeto. Al abdicar de tal dualidad y tomar como tema de reflexión el simple lenguaje, se desvanece la necesidad de un yo trascendental a modo de puente. Ya no hay un sujeto con la función de garantizar la veracidad del lenguaje, su objetividad. Incluso importa muy poco quién sea el sujeto que habla. El lenguaje consiste en una serie de juegos o de actos de habla tipificados conforme a unas reglas.

$\mathrm{Ni}$ en la teoría de los juegos lingüísticos de Wittgenstein, ni en la de los actos de habla de J.L. Austin, cabe la pregunta 
por el yo o por la identidad del sujeto del lenguaje. Es cierto que el juego supone unos jugadores y que el acto de habla presupone uno o varios actantes, pero en ambos casos no es el sujeto quien va a determinar la atención del análisis lingüistico, sino el juego que se juega y el acto que se realiza. No es ia imagen o la idea que yo tengo en la cabeza ni la sensación que siento lo que determina el significado de lo que digo, pues la función representativa es una entre las muchas que desempeña el signo lingüístico. El lenguaje tiene diversos usos, y en cada uno de ellos, la referencia al yo (cuando la hay) tiene un sentido especial. Pensemos -sugiere Wittgenstein- en qué ocasiones diríamos "¿Son éstos mis libros?”, “¿Este es mi pie?”, “¿ ¿Es mía esta sensación?” (Ph.U., 411). Los juegos del lenguaje tienen su "gramática", y los actos de habla han de cumplir unas condiciones de felicidad. Lo cual significa dos cosas: 1) los sentimientos, pensamientos, deseos e imágenes del sujeto son vehiculados por las reglas del lenguaje; 2) la identidad del yo varía según sea el juego o el acto de habla que esté realizando: el yo promete, ordena, bromea o, simplemente, dice; no tiene una identidad propia, independiente del acto que está realizando, antes bien se sumerge en dicho acto el cual le otorga el protagonismo que cada actuación requiere.

"Todo jugar es un ser jugado", escribe Gadamer a propósito del concepto de juego en el contexto de la experiencia artística: "la obra de arte tiene su verdadero ser en el hecho de que se convierte en una experiencia que modifica al que la experimenta. El 'sujeto' de la experiencia del arte, lo que permanece y queda constante, no es la subjetividad del que experimenta, sino la obra de arte misma. Y éste es precisamente el punto en el que se vuelve significativo el modo de ser del juego. Pues éste posee una esencia propia independiente de la conciencia de los que juegan". Así, el juego mismo, y no el jugador, es el auténtico sujeto del juego. Más aún cuando el juego se vive como una "representación para un espectador": los jugadores se sienten trascendidos por el juego, piezas de una actuación que los supera y los dirige.

A partir de esta nueva concepción del lenguaje, al discurso filosófico se le imponía un cambio de sentido. Si el lenguaje no es sólo ni siempre representación del mundo ante un sujeto, 
sino, más que nada, expresión de una forma de vida, la orientación epistemológica, punto de partida de las teorías del conocimiento y de las teorías de la acción, deja de ocupar el lugar prominente. La verdad del objeto o la identidad del sujeto no han de ser ya los problemas fundamentales. La verdad carece de sentido unívoco, y los juegos de lenguaje o los actos de habla requieren distintas condiciones de verdad. El sujeto, por su parte, es una función de los actos que están en juego, o de los juegos que se actualizan; en ningún caso se le permite que reclame una identidad o una importancia por encima de sus varias y diversas representaciones. El lugar predominante lo ocupan ahora las reglas. Sin ellas no hay ni juego ni actos de habla. Sin reglas, el lenguaje no podría cumplir la función comunicativa: posibilidad de participación en el juego o posibilidad de representación del juego para unos espectadores. Las reglas legitiman la función comunicativa del lenguaje del mismo modo que las condiciones de verdad más estrictas legitimaban la función representativa. $\mathrm{Y}$, al parecer, da lo mismo para tales efectos que las reglas vayan en un sentido o en otro: lo importante e imprescindible es que las haya.

Proclamada, desde distintos frentes filosóficos, la ficción del sujeto, el discurso filosófico ha emprendido una dirección ambivalente. Por una parte, asistimos al surgimiento de una serie de filosofias "impersonales": estructuralismo, hermenéutica, pragmática, etc. Por otro, ciertas corrientes de tendencia existencialista lamentan la disolución del yo, es decir, su falta de autenticidad. La sociedad - ha dicho Sartre- nos pide que nos limitemos a cumplir unas funciones, que lleguemos a identificarnos con ellas: "existen cantidad de precauciones para encarcelar al hombre en lo que es, como si viviéramos en el temor continuo de que pueda escapar de ello, de que pueda eludịr su condición" (El Ser y la Nada). El sociólogo Erving Goffmann alude a la cita de Sartre para insistir en su tesis de la dispersión del yo en sus distintos roles. Y A. McIntyre se apoya en ambos para reafirmarse en su convicción de que la sociedad corporativa de nuestro tiempo "es una agencia cuyo moralismo divide la moralidad en partes disociadas"; su discurso sobre las virtudes resulta contradictorio puesto que les pide a los actores sociales que cambien de un escenario a otro, de uno a 
otro carácter, de una a otra moral. Por su parte, Horkheimer clama por la conservación del sujeto como tema de nuestro tiempo: la búsqueda de seguridad, la racionalización de la sociedad, el planning y el consumismo amenazan con la desaparición del individuo; la subjetividad ha pasado del individuo a la colectividad: la casta profesional, el partido, la nación. El individuo ya no tiene que decidir nada: la colectividad lo hace por él. Sólo es preciso que obedezca órdenes.

Por un lado, pues, discursos que parecen expresar la nostalgia de un yo perdido o nunca hallado: los límites de la autenticidad. Por otro, filosofías que preconizan un pensámiento nuevo, otra época del ser. Entre estas últimas se cuentan, además de la filosofía analítica que atiende a la pragmática del lenguaje siguiendo al último Wittgenstein, las reflexiones del también último Heidegger que han abonado el terreno para la corriente hermenéutica. En Holzwege, Heidegger rechaza al sujeto representador, "fantasioso", que se mueve en la imaginatio, que, en lugar de asistir a la desvelación de lo presente, "capta y comprende"; en dicha relación -dice- "lo que domina no es lo presente, sino el ataque". En su lugar, propugna una filosofía no pensada desde la certidumbre del sujeto representador que existe y se pone a sí mismo junto a lo representado: "el subjectum, la certidumbre fundamental, es el estar representado al propio tiempo del hombre representador con lo existente representado, humano o no humano, es decir, con lo objético". Ese sujeto, conciencia, que en la Ilustración se piensa como ser racional, se pensará luego como nación, como raza e incluso como dueño de la superficie terrestre. La dominación y la uniformidad de la técnica amenazan el ser del hombre. "La libertad moderna de la subjetividad se disuelve completamente en la objetividad que le es conforme. El hombre no puede abandonar de suyo ese destino de su esencia moderna o quebrantarla autoritariamente. Mas el hombre puede meditar con un pensar anticipado que el ser-sujeto de lo humano no fue nunca la única posibilidad del incipiente ser del hombre histórico, ni lo será jamás. Una pasajera sombra de nubes sobre una región escondida es el oscurecimiento que pone aquella verdad preparada por la certidumbre de redención del cristianismo 
sobre un acaecimiento que le es negado experimentar". (Sendas perdidas, Losada, 1960, págs. 93 ss.).

La coincidencia entre la crisis del sujeto como reducto de seguridad y certidumbre, y la creciente orientación hacia el estudio del lenguaje no es ocasional. Cuando se empieza a desconfiar no ya de los logros del sujeto trascendental para garantizar la objetividad de lo conocido, sino de la credibilidad que puede ofrecer ese mismo sujeto que, en definitiva, no es sino el sujeto empírico camuflado de universalidad; cuando se empieza a poner en duda la validez absoluta y ahistórica de todo lo que siempre pretendió pasar por absoluto y ahistórico, se descubre el lenguaje como, al mismo tiempo, el lugar del engaño y la terapia para remediarlo. Los sujetos empíricos, desprovistos de la certidumbre proporcionada por ese Sujeto con mayúscula caen en la cuenta de algo demasiado obvio: que su relación con el mundo exterior y la interrelación de los sujetos entre sí se produce por y en el lenguaje.

Pero el lenguaje no es sólo un medio para hablar del mundo, sino para vivir y actuar en él: el lenguaje no describe sólo, sino hace muchas otras cosas cuyo trasfondo es una "forma de vida". A partir de esa concepción que no quiere unificar, sino diferenciar, que no instaura un orden, sino admite órdenes varios, el Sujeto que todo lo fundamenta y lo controla se hace inútil, entre otras razones, porque tampoco tiene ya mucho sentido la pregunta omnipresente por la verdad de lo que hablamos. "El 'enunciado' tradicional es una abstracción, un ideal, y lo mismo su tradicional verdad o falsedad", escribe Austin (How to do Things With Words, pág. 147). La pregunta por la verdad es sustituida por la pregunta por la validez, puesto que el lenguaje es concebido como un comportamiento sujeto a reglas.

Esas reglas no son absolutas; son fruto de una convención expresa o tácita, de tal forma que el desplazamiento de la pregunta por la verdad a la pregunta por la validez parece minimizar nuestra capacidad de pedirle cuentas al lenguaje. De las concepciones de Wittgenstein y Austin, por lo menos, parece desprenderse la conclusión: todo vale siempre y cuando el juego se juegue o el acto se cumpla, siempre y cuando los jugadores o los agentes parezcan estar de acuerdo en el respeto a unas 
mismas reglas. Conclusión que no aceptan, sin embargo, quienes piensan que no basta decir qué reglas hay, sino cuáles son legítimas. El desacuerdo y la incomprensión son hechos con los que tropieza nuestro uso cotidiano del lenguaje. Y el desacuerdo es visto como un obstáculo para la comunicación. Por lo menos, los teóricos de la comunicación dan por supuesto que la finalidad de todo acto comunicativo es el acuerdo, que cuando éste no se da algo funciona como no debe: no está asegurado el uso "justo" del lenguaje por todos y cada uno de los hablantes.

Pero hay más, cuando entran en escena nociones como "validez", “justicia", "acuerdo", el discurso adquiere claras connotaciones éticas. Si hay que buscarle un orden al lenguaje por encima de la desordenada concurrencia de juegos y actos lingüísticos, ¿ cómo fundamentar ese orden? Obviamente, no a partir de otra prescripción entre las muchas que hay vigentes, sino desde la prescripción legitimadora de todas las prescripciones, normas o reglas, la prescripción trascendental. Un nuevo contrafáctico que, por obra de los filósofos del lenguaje, viene a sustituir al Sujeto o a la Razón trascendental kantianos.

Por ese camino discurren Apel y Habermas guiados por la obsesión de encontrarle un garante legitimador a la acción comunicativa. Garante que, según ellos, nos lo da el propio acto de comunicar. Pues toda acción comunicativa es la expresión de intersubjetividad a través de una comunidad de hablantes, la cual cuenta con un contrafáctico: la comunidad ideal de hablantes. Esta ejemplificaría la comunicación en estado puro, transparente y sin trabas, a partir de una total y perfecta simetría entre los hablantes, que haría no sólo posible, sino justo el acuerdo. La comunidad ideal de diálogo encarna la racionalidad.

Vemos, pues, que el lenguaje como medio de comunicación proyecta también su propio trascendental desde donde podrá legitimar sus normas y discurrir hacia la constitución de la sociedad comunicativa racional. De la misma forma que el lenguaje representativo contaba con una forma lógica como condición de posibilidad de la representación, ahora, al desplazar la atención hacia la función comunicativa del lenguaje, necesitamos una condición de posibilidad de la comunicación 
total y racional. Si aquello demandaba el fundamento de un sujeto ideal, esto exige el fundamento de una comunidad ideal. Ahora bien, ¿ hasta qué punto es suficiente la comunidad ideal para legitimar la comunicación real, y hasta qué punto podemos formular de este modo la pregunta por la validez?

Más radicalmente, $\dot{c}$ hasta qué punto es ésa la pregunta filosófica por excelencia, la última pregunta? Obviamente, si nos interesa sobre todo la función comunicativa del lenguaje y, por ende, zanjar los desacuerdos que la obstaculizan, habrá de interesarnos también la validez de lo que decimos, puesto que si todo valiera igual en el lenguaje, la arbitrariedad y la anarquía harian imposible la mutua comprensión. Esa validez, sin embargo, habría de determinarse bien señalando cuáles son los referentes reales de las palabras, bien tratando de comprobar si se cumplen las normas de la comunicación lingüística. Pero comprobamos que los términos con un referente claro y unívoco ocupan una mínima extensión del universo lingüístico. Por otro lado, las condiciones de la comunicación ideal no se cumplen nunca: si se cumplieran, el lenguaje sobraría. Vemos que la filosofia ha pasado a considerar el lenguaje desde otra óptica -de la representación a la comunicación-pero sin variar de paradigma. Así, la pregunta por la verdad queda sólo levemente modificada por la pregunta por la validez.

Los últimos escritos de Habermas son un ejemplo claro de la ambivalencia encerrada en ese contrafáctico de la comunicación ideal que, supuestamente, debería servir de criterio de validez de las normas de uso lingüístico. De las normas de uso del lenguaje valorativo, claro está: el lenguaje que establece las normas de la acción. En efecto, piensa Habermas que "la fundamentación de las normas requiere la realización de un discurso real, no monológico", esto es la realización de la comunidad ideal de diálogo. Pero esa afirmación admite dos interpretaciones fundamentalmente distintas: 1) o pensamos, al modo hegeliano, que ese discurso real se está realizando ya de hecho, históricamente; 2) o pensamos que jamás llegará a realizarse satisfactoriamente por lo que la validez absoluta del lenguaje normativo no quedará jamás probada. A mi entender, Habermas vacila entre ambas posturas sin llegar a pronunciarse claramente por ninguna de las dos. Pero entre Hegel y Kant 
no hay término medio. No lo hay si seguimos empeñados en encontrar la validez absoluta, la razón histórica o suprahistórica. $\mathrm{Si}$, por el contrario, nos atenemos a lo que hay, un lenguaje y unas situaciones de comunicación que sólo propician diálogos distorsionados e imperfectos o acuerdos ilegítimos, producto del dominio de unos sobre otros y no de la reciprocidad, si partimos de la realidad de un desacuerdo profundo, $\dot{i}$ no sería más provechoso y constructivo olvidar la pregunta por la validez y sustituirla por el intento de averiguar cuáles son las razones de nuestros desacuerdos? De muy poco o de nada sirve denunciar ideologías frente a una verdad inalcanzable y remota. Más interesante es, en cambio, indagar en el porqué, las razones de nuestras creencias o ideologías. Buscar la explicación social del conocimiento, en lugar de obstinarnos en la idea de demarcar el conocimiento válido del que no lo es.

Uno de los hallazgos felices puesto de manifiesto por la discusión en torno a la "falacia naturalista" ha sido el poner en duda la posibilidad de construir juicios descriptivos a ciertos propósitos, o de distinguir claramente entre la descripción y la prescripción o la valoración. Difícilmente sabremos pergeñar descripciones puras al hablar de ciertos temas que suponen una carga ideológica - una diversidad de opiniones y creencias- considerable. $Y$ esos son los temas que provocan desacuerdos. En el fondo de muchas supuestas descripciones, informaciones, hay una valoración encubierta. Más aún: entre esos juicios descriptivo/valorativos (o descriptivo/prescriptivos) que supuestamente transmiten información sobre la realidad que más nos afecta, los hay que son ellos mismos "reglas constitutivas" del mismo lenguaje, y los hay -la mayoría de ellosque sólo expresan opiniones, apreciaciones sobre la realidad, a veces sólidamente establecidas y aceptadas, pero, en cualquier caso, discutibles y modificables. Así, no son del mismo tipo, ni han de merecer el mismo reconocimiento o legitimación, enunciados como "las promesas deben cumplirse", y enunciados como "la familia es la célula básica de la sociedad". El primer ejemplo puede considerarse un juicio analítico (como lo serían también "la justicia es buena" o "matar es malo"), pues define o constituye el acto de la promesa. El segundo, por el contrario, aparece como una convicción no universalmente 
aceptada, o aceptada con reparos. Son esos enunciados del segundo tipo, los que no debemos dudar en llamar "descriptivoprescriptivos", los que hacen difícil la comunicación y constituyen la raíz de los desacuerdos.

A la luz de tales ejemplos es posible decir que el contrafáctico propuesto por Apel y Habermas pertenece al tipo de las reglas constitutivas del lenguaje o de la comunicación misma. Del mismo modo que la promesa hecha con la intención de no cumplirla no es promesa, habrá que decir que la acción comunicativa que no aspira a la comunicación transparente, justa, libre y, en consecuencia, al acuerdo, no es comunicación racional, antes simulacro de ella. Tesis, sin duda, cierta -sólo la comunicación o el diálogo que se ajusta al ideal comunicativo es racional-, pero ante la que debemos preguntarnos: $\dot{c}$ adónde nos lleva? $\dot{c}$ Nos permite avanzar algo en el intento de explicar o poner de manifiesto las opiniones y creencias ocultas en el uso del lenguaje? Creo que no. Creo que el contrafáctico nos permite tan sólo denunciar y negar la supuesta racionalidad de nuestros acuerdos fácticos, denunciar la ideología como tal, pero no dar el paso que pretende de la ideología a la verdad. Quede claro, sin embargo, que al criticar dicha tesis no propongo en ningún modo otra que la sustituya. Puesto que asumo que la legitimación o el acuerdo racional, absoluto, sólo es viable acerca de principios muy generales, que son los principios indiscutibles -las "reglas constitutivas"-, propongo abandonar esa búsqueda y que nos limitemos a validaciones parciales, relativas, de medio alcance. Esas que el propio $\mathrm{Ha}-$ bermas adjudica a los valores relativos del Lebenswelt. Que nos limitemos a eso, digo, pero para proseguir la investigación, para ir más allá de los acuerdos parciales e insuficientes en la indagación de las razones que impiden un acuerdo nítido y puro. Razones que, como decía antes, se revelan en la constatación de que "el lenguaje de los afectos" o el lenguaje referido a las cosas que más nos afectan no es usado inequívocamente. Dicho brevemente, el desacuerdo radica en el hecho de que no se comparten unos usos semánticos o reglas de significado, pese a que estemos sirviéndonos de las mismas palabras.

En efecto, y abundando en lo dicho hace un momento, el desacuerdo que engendra conflictos aparentemente irresolu- 
bles por una vía racional, descansa y se nutre en esa ambigüedad de ciertos términos o formas de hablar, que nos impide clasificarlos como puramente descriptivos y prescriptivos. Deriva de la insuficiencia representativa del lenguaje. La pregunta: ¿qué queremos decir cuando decimos "bueno", "sincero", "fiel", "justo"?, si se entiende adecuadamente, no está pidiendo una definición, sino expresa la incomodidad ante ciertos términos que carecen de un referente unívoco y claro. No son ideas "simples", dirían los empiristas clásicos, y, por ello - habría que añadir - su uso es más prescriptivo que descriptivo. Incluso no basta conocer sus reglas de uso semánticọ: que "deber" moral significa "universalidad", que "justicia" significa "igualdad". Porque tales reglas remiten a otro concepto tanto o más equívoco que el anterior. Stêvenson vio diáfanamente que la raíz de los desacuerdos son las creencias y las actitudes. Cuando éstas no son compartidas, somos víctimas del uso "emotivo" de los términos y aplicamos las mismas palabras a realidades distintas. ¿A qué llamamos "delito", "tortura", "soberanía"? Depende de quién use la palabra. ¿Cuestión de nombres? Sí, de aquellos nombres para los que no sirven las definiciones ostensivas.

Aristóteles dijo en La Política que "la naturaleza no ha hecho nada en vano... y ha dotado al hombre de lenguaje para que distinga lo útil de lo perjudicial, lo justo de lo injusto, lo bueno de lo malo" (Política, 1253 a 10). Ahora bien, el lenguaje, al constatar una distinción valorativa, le da realidad. En cierto modo, la crea. Tratándose del pensamiento reflexivo, la producción de lenguaje es concomitante a la producción de las ideas designadas por el lenguaje. A esas ideas, elaboradas por el entendimiento, Locke las llama "modos mixtos", en los cuales, el nombre es la esencia de la idea: "los nombres de los modos mixtos significan siempre sus esencias reales, que son obra de nuestras mentes": Pero lo material es el nombre, no la idea. Y es así que aquél se aprende antes que ésta. Cuando el referente de un nombre es una cosa, realidad ostensiva $u$ ostensible, la transmisión del significado es fácil y clara. Los equívocos y las ambigüedades empiezan con los nombres de las ideas, pues ¿ cómo saber qué idea se esconde bajo los varios usos de palabras como "libertad", "asesinato" o "robo"? Locke ve lú- 
cidamente el problema y afirma: "Cuando se piensa que un hombre tiene una idea falsa de la justicia, de la rectitud o de la gloria, no es por otra razón, sino porque su idea no coincide con las ideas que cada uno de estos nombres significa en otros hombres". La dificultad de las ideas morales, su indemostrabilidad, se explica por dos razones: la falta de correspondencia sensible y la complejidad que encierran. No hay relación biunívoca del nombre a la idea, como si ésta fuera un dato sensible, sino que el nombre refiere a un concepto cuyos sentidos no se concretan en unas cuantas notas definitorias. Así, la significación es "incierta", escribe Locke, o, como había dicho Hobbes, "inconstante". De ser posible la frialdad en el uso de tales nociones, "si los hombres trataran de los asuntos morales con el mismo método e indiferencia con los que se enfrentan a las verdades matemáticas", podrían resolverse las dificultades y los equívocos. Pero abordar la ética more geometrico es inviable. También Locke se da cuenta y añade que "no son de esperar grandes cosas en este sentido en tanto los deseos de fama, de riqueza o de poder lleven a los hombres a abrazar las opiniones que están más de moda, y a buscar después argumentos bien para realzar su belleza, bien para barnizarlas y cubrir sus deformidades, sin pensar que nada hay más bello para el ojo como la verdad lo es para la mente, ni nada tan deforme e irreconciliable para el entendimiento como la mentira" (J. Locke, An Essay concerning Human Understanding, II, XXXII, II y IV, II, 1920).

La falta de coincidencia ideológica parece, pues, una constante que se refleja en la imprecisión semántica del lenguaje valorativo. Locke piensa que la imperfección de las palabras sería subsanable si no nos dejáramos llevar por opiniones, modas e intereses. La verdad, es decir, la unanimidad en torno a la idea, la universal concordancia entre idea y nombre sería posible si el lenguaje fuera perfecto, es decir, directo y sin ambigüedades. También Habermas parece estar pensando en un lenguaje así cuando proyecta la comunidad ideal, donde el acuerdo es un hecho y, más importante aun, desde donde es posible rechazar las ideas o los valores no susceptibles de acuerdo. Al igual que Sócrates que pretendía "fijar" y "sujetar" las opiniones por medio de la razón, como si fueran las es- 
tatuas de Dédalo, Habermas pretende "fijar" lo que debe ser dicho mediante la postulación de una comunidad perfecta de hablantes.

Sin embargo, el lenguaje puro y transparente, claro y distinto, sin equívocos, no es el nuestro. Es, en todo caso, el lenguaje que Benjamin atribuia a los dioses cuyos nombres nombran con una nitidez más allá del alcance humano. Martin Jay se ha referido bellamente a ello cuando dice que, para Benjamin, "'en el principio fue el Verbo' significaba que el acto de creación de Dios consistía parcialmente en la concesión de nombres. Estos nombres expresaban, por supuesto, perfectamente a sus objetos. Sin embargo, el hombre, creado como fue a imagen de Dios, tenía el don singular de nombrar. Pero sus nombres y los de Dios no eran los mismos. Como resultado, se desarrolló allí una separación entre el nombre y la cosa, y se perdió la adecuación absoluta del discurso divino. Para Benjamin, la lógica formal era la barrera que separaba el lenguaje del Paraíso de su contrapartida humana. El hombre tendía a sobrenombrar las cosas por medio de abstracciones y generalizaciones... la función de la crítica cultural consistía en recobrar la dimensión perdida en el discurso de Dios mediante la decodificación hermenéutica de las diversas aproximaciones inferiores del hombre" (Martin Jay, La imaginación dialéctica, Taurus, Madrid, 1974, pág. 422).

En efecto, esa tarea decodificadora en busca de una supuesta dimensión perdida es la que corresponde emprender a la filosofía. Si el lenguaje no es concebido sólo como el "espejo", la representación de una realidad exterior al entendimiento, sino como el vehículo de relación y de comunicación intersubjetiva, el discurso filosófico deberá olvidar no ya la pregunta por la verdad, sino incluso la pregunta por la validez del lenguaje que se habla. Y, en su lugar, preocuparse por profundizar en las raíces de la confusión, la discrepancia, el desacuerdo, la incomunicación. Seguramente no llegará jamás a saber pronunciar el discurso puro, porque le faltaría asimismo sabiduría para entenderlo. Pero sabrá que ha hecho lo posible por acercarse a él en un esfuerzo por traducir los varios lenguajes terrenales.

$\mathrm{Si}$, en efecto, el desacuerdo proviene de las impurezas del 
lenguaje, que no acaba de hacerse transparente, el empeño por llegar a una claridad mayor puede muy bien concebirse como la tarea emancipatoria. Para lo cual es preciso trascender todas aquellas claves del lenguaje - referentes, reglas- que conciben al hablante como hablante genérico. Habermas entiende que el lenguaje distorsionado -el nuestro - necesita una terapia similar a la del psicoanálisis, el cual es "un cierto tipo de análisis lingüístico". El neurótico habla incomprensiblemente, frustrando las expectativas normales, y ello ocurre porque forma parte de una comunidad cuya estructura intersubjetiva no respeta la identidad inalienable del ego. La incongruencia entre lenguaje privado y lenguaje público, la incapacidad de integrar simbólicamente las propias vivencias, es el síntoma claro de la represión y manipulación comunicativa. Pues el sistema lingüístico no es universal, no responde a las necesidades e intereses de todos por igual.

Si esto es así, la realidad del desacuerdo, de la imprecisión y de la opacidad comunicativa constituirán la plataforma de la emancipación humana. Más que aplaudir los acuerdos, que siempre serán sospechosos de dominio de unos sobre otros, conviene que la tarea crítica vaya dirigida a constatar y profundizar en los desacuerdos, puesto que, en el fondo de todos ellos, se encuentra un yo que se resiste a perderse en la identidad colectiva. Desde la realidad conflictiva, el yo -que no es ni mero dato empírico ni juez trascendental, ni sabe definir su propia identidad - se siente diferente, no plenamente integrado. Incitado, por tanto, a buscar las razones de su desequilibrio. Tal vez del sujeto moral no sea posible decir nada coherente: pero existe, como Wittgenstein afirmó. Es el sujeto de la voluntad que quiere cambiar el mundo, y empieza por no identificarse ni confundirse del todo con él. Empieza por ser consciente de que "el mundo no es mi mundo". Ahí radica la diferencia entre el sujeto de la ética y el sujeto del conocimiento: para éste, los límites del lenguaje son los límites del mundo, para el otro, no. No es extraño que el sujeto del conocimiento estuviera condenado a muerte desde el momento en que se pretendió que fuera el garante de un conocimiento neutral, objetivo. ¿Qué falta hacía el yo en ese proceso? Pero la acción es un asunto distinto, que sí precisa de sujetos, siempre y cuan- 
do éstos se mantengan como seres autónomos y no queden circunscritos en unos rasgos generalizables. A fin de cuentas, ésa y no otra es la razón del discurso ético: la tensión entre lo general y lo particular. Y el logro de tal discurso, "la construcción del yo", esto es, saber mantener un yo "más largo" que el del individuo dominado por el egoísmo. Así lo entendió y lo propuso, breve pero lúcidamente, George $\mathrm{H}$. Mead: "el método de tener en cuenta todos los intereses que constituyen a la sociedad, por una parte, y al individuo, por otra, es el método de la moral". La comunicación lingüística -la acción comunicativa, como la llama Habermas-debería darse por validada y legitimada si se ajustara a las directrices de tal método. 